\title{
An estimation of the amount of dissipated alloy elements in special steel from automobile recycling
}

\author{
Zhengyang Zhang ${ }^{1,}{ }^{*}$, Kentaro Takeyama $^{2}$, Hajime $\mathrm{Ohno}^{2}$, Kazuyo Matsubae ${ }^{1}$, Kenichi Nakajima ${ }^{3}$, and \\ Tetsuya Nagasaka ${ }^{2}$ \\ ${ }^{1}$ Graduate School of Environmental Studies, Tohoku University, Sendai 980-0845, Japan \\ ${ }^{2}$ Graduate School of Engineering, Tohoku University, Sendai 980-0845, Japan \\ 3 National Institute for Environmental Studies, Tsukuba 305-8506, Japan
}

Received: 18 October 2018 / Accepted: 25 January 2019

\begin{abstract}
According to the concept of a circular economy, further promotion of reuse and recycling might aid in closing the loop. However, material recycling may cause various types of material losses due to thermodynamic limitations and product complexity. In this study, we focused on automobile engines and their reuse, with the aim of quantifying the amount of dissipated steel alloy and its constituent elements (nickel and chromium) from the engine recycling process. We also elaborated upon their dissipation paths by using the MaTrace model [S. Nakamura, et al., MaTrace: Tracing the fate of materials over time and across products in open-loop recycling, Environ. Sci. Technol. 48, 7207 (2014)]. We evaluated the impact mitigation of material dissipation and the effects of reuse on the extension of product service life. We found that $22 \%$ of steel, $21 \%$ of nickel, and $63 \%$ of chromium was dissipated in total after 50 years; typically, nickel dissipates during the recovery process while chromium does so during the refinery process. Although the impacts on the reduction of material losses remained nearly the same after replacing 40 of $100 \%$ material recycling to parts reuse, greater possibilities could be achieved with respect to the service life extension of products when compared with $100 \%$ recycling.
\end{abstract}

Keywords: automobile engine / recycling / reuse / MaTrace

Résumé. Estimation de la quantité d'éléments d'alliage dissipés dans l'acier spécial provenant du recyclage automobile. D'après le concept d'une économie circulaire, promouvoir davantage la réutilisation et le recyclage pourrait aider à boucler la boucle. Toutefois, le recyclage des matériaux pourrait entraîner divers types de pertes en raison des limites thermodynamiques et de la complexité du produit. Dans cette étude, nous nous sommes attardés aux moteurs automobiles et leur réutilisation, dans le but de quantifier la quantité d'alliage d'acier dissipé et de ses éléments constitutifs (nickel et chrome) étant issus du processus de recyclage des moteurs. Nous avons, par ailleurs, élaboré leurs chemins de dissipation en utilisant le modèle MaTrace [S. Nakamura, et al., MaTrace: Tracing the fate of materials over time and across products in open-loop recycling, Environ. Sci. Technol. 48, 7207 (2014)]. Nous avons évalué l'atténuation de l'impact de la dissipation des matériaux et les effets de la réutilisation sur l'allongement du cycle de vie du produit. Nous avons constaté que $22 \%$ de l'acier, $21 \%$ du nickel et $63 \%$ du chrome étaient complètement dissipés après 50 ans ; en général, le nickel se dissipe pendant le processus de récupération, tandis que le chrome se dissipe pendant le processus de raffinage. Bien que les incidences sur la minimisation des pertes matérielles soient demeurées presque les mêmes après le remplacement de $40 \%$ de $100 \%$ du recyclage des matériaux pour la réutilisation des pièces, des possibilités plus grandes pourraient être réalisées en ce qui concerne l'allongement du cycle de vie des produits par rapport à un recyclage à $100 \%$.

Mots clés: moteur automobile / recyclage / réutilisation / MaTrace

\section{Introduction}

The traditional take-make-dispose industrial production model has relied on large quantities of available resources. Continued global economic growth and social development

\footnotetext{
* e-mail: zhang.zhengyang.q7@dc.tohoku.ac.jp
}

have increased the demand for material resources. For example, global material extraction is forecasted to grow to $\sim 82$ billion tons by 2020 [1], and 183 billion tons by 2050 [2] based on different starting assumptions. increasing and volatile commodity prices [3] and the supply risk associated with chemical elements [4] add to these complications. these changes point to the need for more sustainable and efficient approaches with regard to resource consumption. 
In recent years, the circular economy has been proposed as a mainstream concept to achieve maximum resource utilization efficiency. The net cost savings potential for complex durable materials with medium lifespans is estimated to be up to 630 billion US dollars (USD) per year in the European Union (EU) alone, accounting for $23 \%$ of the current total input cost. The benefits to the automotive sector are the highest [5]. In the circular economy model, product longevity is extended for as long as possible through reuse, repair, remanufacturing, upgrades, and retrofits, and goods that are at the end of their usable lifespans are converted into as-new resources for others by recycling their constituent materials [6]. Further promotion of reuse and recycling allows for a diversified circulation of materials at all production levels and keeps them out of landfills, thus contributing to closing the loops in product lifecycles.

Recycling has been considered to be an effective means of material conservation. Unfortunately, various types of material losses are unavoidable in metallurgical recycling processes due to thermodynamic constraints on recoverability. According to Nakajima et al. [7], most chemical elements tend to be distributed into the slag or gas phases in steel, from which they are difficult to recover. Although some elements, such as tungsten (W), molybdenum (Mo), cobalt $(\mathrm{Co})$, and nickel $(\mathrm{Ni})$, remain in the metal phase, they cannot be recovered even after changing the activity coefficients of the oxidation products. This thermodynamic phenomenon strongly indicates that loss of or contamination by these unrecoverable elements could occur in conventional steel recycling systems. This issue has also been noted in the material flow analysis (MFA) field. Current open-loop recycling of metals is always associated with losses of quality and functionality of the recovered materials compared to the primary materials, dissipation of alloying elements, and dilution losses when contaminants in secondary metals must be diluted with virgin resources to an acceptable level [8-10]. In this study, the term "openloop recycling" refers to the cascade approach for recycling, that is, the recycled material is sent to other product systems and its inherent properties are changed (e.g., lowered mechanical performance). The recycled material cannot totally replace the virgin material due to its impurities [11-14]. Additionally, Reuter et al. [15] noted that materials are inevitably lost at each step of the recycling process due to the complexity of product designs and the interactions within recycling systems.

Given the disadvantages of material recovery, extending the service life of products before repurposing or recycling is of greater benefit. Using materials to their maximum extent could avoid resource losses, save raw materials and energy, reduce emissions and by-products of some nations, and greatly reduce the volumes of waste generated [6]. Furthermore, reuse can retain the functionality of products and their components by using them for their original purpose or with minimal improvements or changes.

Anderson et al. [16] estimated the input of 25 scarce metals to Swedish end-of-life vehicle (ELV) recycling using MFA. Their results indicated that only platinum may be functionally recycled, and there was considerable risk of losing scarce metals in ELV recycling. Ohno et al. [8] quantified the amounts and losses of recyclable $\mathrm{Cr}, \mathrm{Ni}$, and Mo in steel during ELV recycling by using waste inputoutput MFA (WIO-MFA). Takeyama et al. [10] applied the material-trace (MaTrace) model built by Nakamura et al. [9] to evaluate the losses of $\mathrm{Ni}$ and $\mathrm{Cr}$ associated with steel recycling, and the possibility of reducing the loss of these alloy elements by implementing scrap sorting technologies. Furthermore, Nakamura et al. [17] developed the MaTracealloy model by focusing on linkages within materials, and applied it to quantify the losses of the steel alloying elements $\mathrm{Cr}$ and Ni over the multiple life cycles of products, along with compositional details among different products and alloys under alternative sorting schemes. They also quantitatively demonstrated the significance of scrap sorting as an advanced method of material recycling. However, none of these studies have considered the reuse of parts and components in their original functions. Thus, the effects of reuse on reducing material losses and shortening product and component life cycles have not yet been critically evaluated.

An automobile engine unit consists of $45.5 \mathrm{~kg}$ of alloyed steel, $47.8 \mathrm{~kg}$ of aluminum, $70.8 \mathrm{~kg}$ of cast steel, $7.1 \mathrm{~kg}$ of carbon steel, $1.8 \mathrm{~kg}$ of sintered alloy, and $5.3 \mathrm{~kg}$ of nonmetal [18]. The term "engine" refers to internal combustion engines for motor vehicles, related parts, fixtures, and accessories (radiators, oil strainers, oil filters, pistons, inlet valves, exhaust valves, cylinders, carburetors, air cleaners, and fuel injection devices). In this study, we focus on alloyed steel. Currently, these alloyed steels are commonly recovered as iron scrap, and many of the alloying elements are lost during the electric arc furnace (EAF) carbon steel production process. However, a deep understanding of the fates of such alloys entering engine recycling is lacking. In this study, we focus on the automobile engine and consider the effects of its reuse, with the purpose of clarifying the volumes and pathways of dissipated steel and alloying elements ( $\mathrm{Ni}$ and $\mathrm{Cr}$ ) in engines recycled in Japan using the MaTrace model. We also analyze the mitigated impacts on material losses and the effects of extending product and component service life by reuse.

\section{Materials and methods}

\subsection{Model}

The MaTrace model is a dynamic WIO-MFA model that can trace the fate of a single material incorporated within different end-of-life products over successive rounds of openloop recycling (i.e. cascade approach for recycling). It also takes into consideration the scrap quality and losses incurred during conversion processes [9]. Takeyama etal. [10] extended the scope of this original model to multiple materials, including steel, $\mathrm{Ni}$, and $\mathrm{Cr}$. However, scenario analyses using MaTrace, to evaluate the impacts of reusing products and components, are still lacking. To fill this gap, we further extended the scope of the multi-material MaTrace model by incorporating reuse, as shown in Figure 1.

The parameters are as follows: discard rate of products $(\varphi)$, reuse ratio of used parts from end-of-life products $(\alpha)$, the distribution ratio of end-of-life products to the material recycling process $(1-\alpha)$, recovery yield of obsolete scrap $(\gamma)$, refining yield of recovered scrap in the metallurgical 


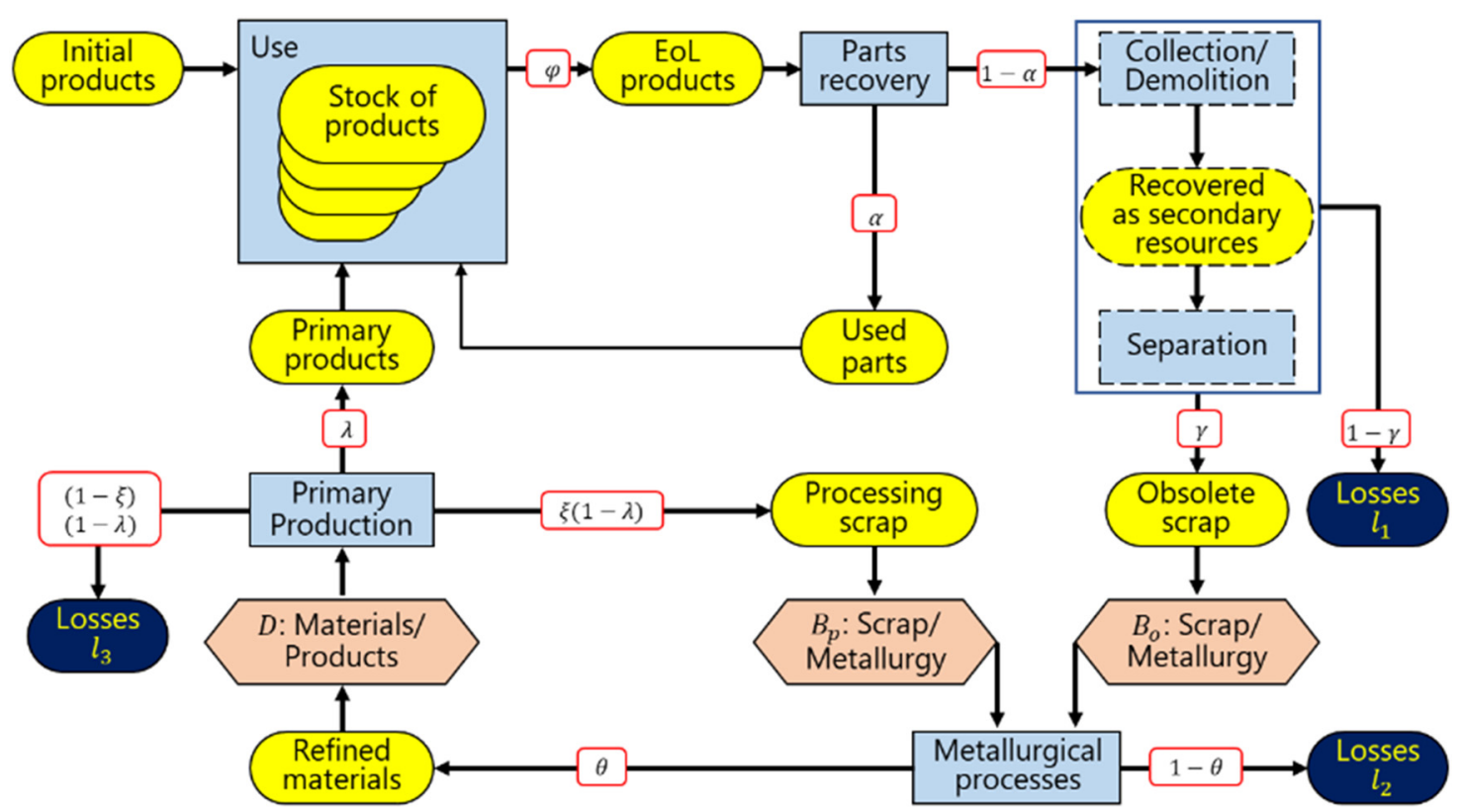

Fig. 1. Scope of the reuse extension of the MaTrace model in this study.

Fig. 1. Portée de la prolongation de la réutilisation du modèle MaTrace dans cette étude.

process $(\theta)$, the yield ratio of refined material used in the production of final products $(\lambda)$, recovery yield of processing scrap in the production process $(\xi(1-\lambda))$, and process yield losses for $(1-\gamma),(1-\theta),(1-\lambda)$, and $(1-\xi)$.

\subsubsection{Calculation of the material stock and its losses}

The stock of $x_{i}(r), r \leq t$, in use at $t, \bar{x}_{i}(t)$, gives the portion of material embedded in the stock of product $i$ at $t$ :

$$
\bar{x}_{i}(t)=\sum_{r=0}^{t}\left(1-\sum_{s=0}^{t-r} \varphi_{i}(s)\right) x_{i}(r)
$$

where $i$ is product; $t, r, s$ are different times in the product's life-cycle, $x_{i}(r)$ is the mass of the material in product $i$ produced at time $r$, and $\varphi_{i}(s)$ is the fraction of product $i$ that is discarded after $s$ years of use.

The total aggregate loss (i.e., losses occurring in recovery scrap of discarded products, refining scrap, and manufacture of final products) at $t$ is:

$$
\bar{l}(t)=\sum_{r=0}^{t} l(r)
$$

with the mass balance condition for $t \geq 0$ being:

$$
\sum_{i=1}^{n} \bar{x}_{i}(t)+\bar{l}(t)=\sum_{j=1}^{n} x_{j}(0) .
$$

The right-hand side of equation (3) refers to the initial endowment of the material in the system, while the lefthand side gives its distribution over time until year $t$ in products and losses. The term $x_{j}(0)$ denotes the initial endowment, and $j$ refers to the engine [9].

\subsection{Data}

The data used in this study were sourced from the WIOMFA database, which was developed by Ohno et al. [8] based on the 2005 Input-Output Tables for Japan [19]. The database used in this study comprised 466 product sectors, 58 crude steel sectors, and 27 steel species. The material composition matrix and material transition matrix were calculated from the WIO-MFA data by referring to the relevant literature [8-10]. The refining yields for each element and each steel type were preset based on previous studies [20,21]. To determine the effects of engine reuse, we considered six categories of final products: automobiles (engines), automobiles (others), civil engineering structures, buildings, machines, and all others, and three types of losses (i.e., production loss, refinery loss, and recovery loss).

Two scenarios were modeled in this study:

- Business-as-usual (BAU) scenario: it was assumed that all the engines recovered from ELVs were scrapped for material recovery, and none were reused. Therefore, the reuse ratio $(\alpha)$ was zero while the distribution ratio to material recycling $(1-\alpha)$ was 1 ;

- Reuse-oriented (RO) scenario: it was assumed that $40 \%$ of the engines recovered from ELVs were reused, and the rest $(60 \%)$ were scrapped for material recovery, which was calculated based on information from a 2014 survey conducted by the Japanese Ministry of Economy, Trade and Industry [22]. The reuse ratio $(\alpha)$ was 0.4 , while the distribution ratio to material recycling $(1-\alpha)$ was 0.6 .

Moreover, the analytical conditions were as follows: - the initial product was the engine; 
- the modeling period (timespan of product evolution) was calculated to be 50 years;

- the average lifetimes of final products were set as follows: automobiles (engines), automobiles (others), machines, and others for 12 years; buildings for 29 years; civil engineering structures for 35 years; and containers for 1 year. The average lifetime of the reused engine was set to 12 years, the same as for new products. The lifetimes that differed were reflected in the parameter for time, namely, $s$ in equation (1);

- the exported engines recovered from ELVs would be completely reused and then recycled under the conditions currently practiced in Japan. However, it was estimated that $36 \%$ of the engines recovered from ELVs were exported to other countries, and only $4 \%$ were reused in the domestic market [22]. Here, we focus on the impact of reuse as a matter of convenience;

- with regard to the recycling conditions for obsolete scrap, $100 \%$ of Ni-containing stainless steel was input into Nicontaining stainless steel, while the other materials were completely recycled as carbon steel scrap.

\subsection{Evaluation criteria for service life extension potential}

The ratio of the material being recycled in the engine to the total amount of material in products and losses was adopted as a criterion for evaluating the potential for product life extension. The portion of material in products $\bar{x}_{i}(t)$ and losses $\bar{l}(t)$ are given by equations (1) and (2) respectively. Referring to $\iota_{i j \tau}$ as the amount of material $i$ recovered in engine $j$ at time $\tau$, the potential of extending the service life of material $i$ in engine $j$ at time $\tau, E_{i j}$, is given by:

$$
E_{i j}=\frac{\sum_{\tau=1}^{t} \iota_{i j \tau}}{\sum_{\tau=0}^{t} \sum_{i=1}^{n} \bar{x}_{i}(\tau)+\bar{l}(\tau)},
$$

where $i$ is a material (steel, $\mathrm{Ni}$, or $\mathrm{Cr}$ ), $j$ is the engine, $\tau$ is time, $t$ is the modeling period (50 years), and $E_{i j} \in(0,1)$.

For simplicity, Figure 2 is given as an example to show the relationship among the operators in equation (4). The numerator $\sum_{\tau=1}^{t} l_{i j \tau}$ on the right-hand side of equation (4) corresponds with the red area, labeled as letter A, and the denominator $\sum_{\tau=0}^{t} \sum_{i=1}^{n} \bar{x}_{i}(\tau)+\bar{l}(\tau)$ on the right-hand side of equation (4) corresponds with the sum of all the areas (namely, A, B, and C).

\section{Results}

\subsection{Mitigated impacts on material dissipation}

According to the mass balance condition in equation (3), the portion of material that is embedded in the stock of products (Eq. (1)) and the portion in accumulated losses (Eq. (2)) always adds up to the initial endowments. Following this property of the MaTrace model, Figure 3 shows the

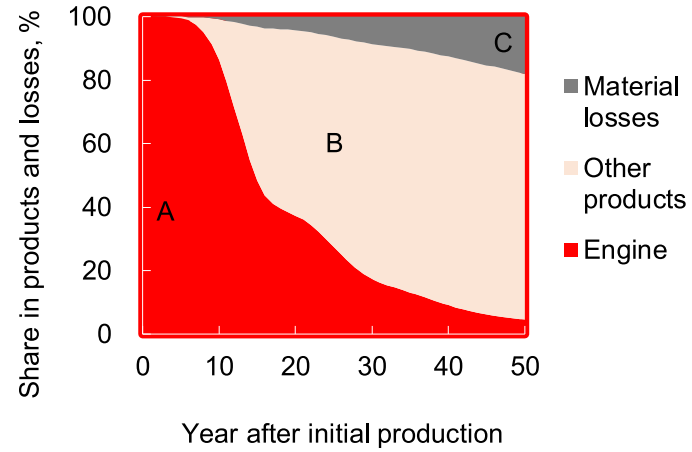

Fig. 2. Image of the evaluation criterion.

Fig. 2. Image du critère d'évaluation.

transitions in the composition of material stock in different products and their losses during 50 years. The horizontal axis shows the year after initial production. The vertical axis shows the percentage for 6 product categories and 3 loss categories. The red composition represented in the figure shows the amount of material (initially used for engines) that is recycled into new engines over a period of 50 years. The amounts of material recycled into other automobile component parts, buildings, civil engineering structures, machines, and other products are highlighted in deep red, green, orange, blue, and yellow, respectively. The light and dark gray areas represent different material losses.

The top panel of Figure 3a shows that under the BAU scenario, the portion of steel recovered in products in the first 20 years following initial production is estimated to be $93 \%$, of which engines accounted for less than $1 \%$, automobiles (others) for $8 \%$, buildings for $36 \%$, civil engineering structures for $30 \%$, machines for $12 \%$, and other products for $6 \%$. After 50 years, the portion distributed to products declined to $78 \%$, with buildings accounting for $31 \%$, civil engineering structures $36 \%$, machines $5 \%$, and other products $6 \%$, while around $22 \%$ was lost during the refinery and material recovery stages. Conversely, in the RO scenario, the percentage of steel used in products was $96 \%$ after 20 years, with $38 \%$ remaining in engines, and $48 \%$ remaining in buildings, civil engineering structures, and machines. After 50 years, $82 \%$ of the steel was still present in the products, with buildings and civil engineering structures making up a large share of $66 \%$. The remaining $16 \%$ of the steel was lost during recycling. From the above comparison, there was no significant difference in the total amount of steel loss between the two scenarios.

The middle panel of Figure $3 \mathrm{~b}$ shows that Ni shared a fate similar to that of steel throughout the 50-year period. Under the BAU scenario, the distribution revealed that $98 \%$ of $\mathrm{Ni}$ was recovered in products after 20 years, wherein buildings, civil engineering structures, and machines received roughly equal shares (of around $25 \%$ ), and shares of lower than $1 \%$ were observed for engines, $9 \%$ for automobiles (others), and $14 \%$ for other products. Fifty years later, the portion left in the products dropped to $78 \%$, $57 \%$ of which was sent to buildings and civil engineering structures, $12 \%$ to machines, and $9 \%$ to other products, 
BAU Scenario

(a) Steel

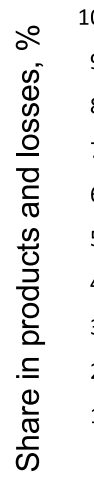

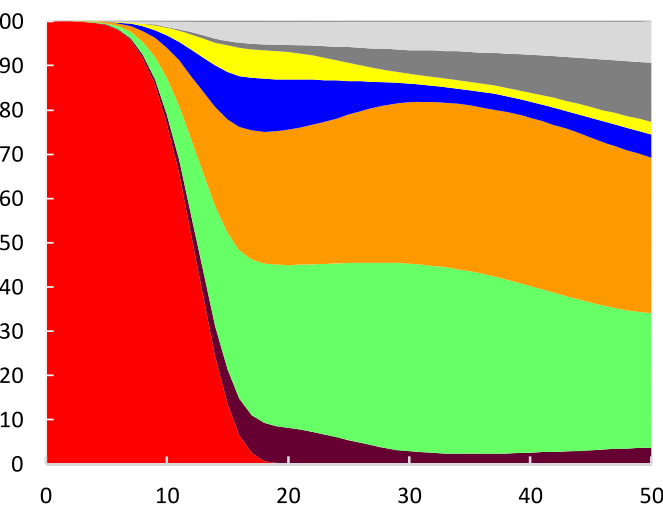

(b) $\mathrm{Ni}$

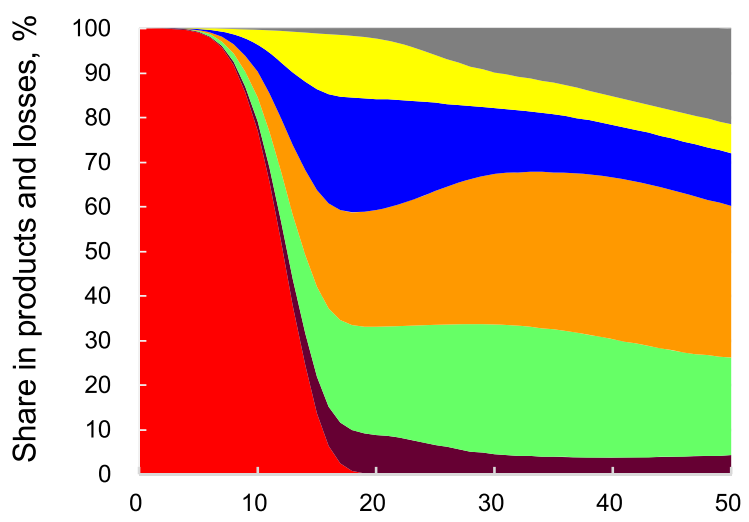

(c) $\mathrm{Cr}$

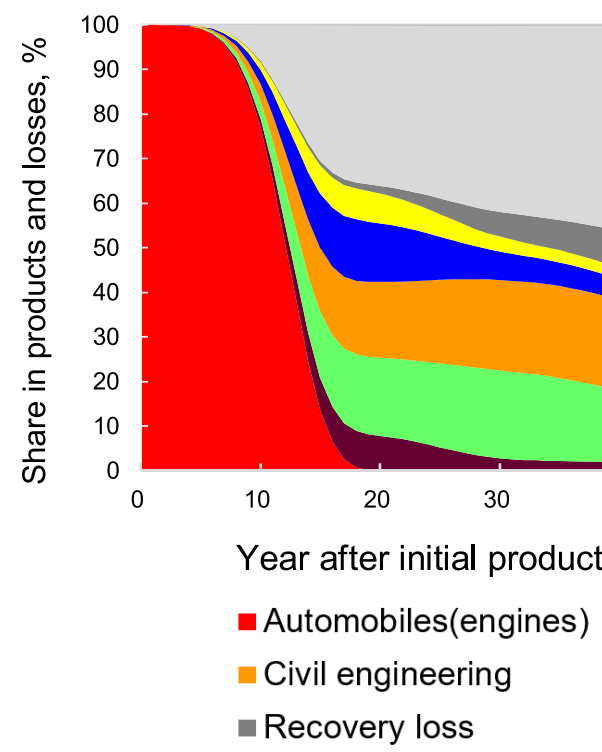

Fig. 3. Transitions in the compositions of the stocks and losses of steel, Ni, and Cr during the modeling period (50 years). Results of the BAU scenario (left) and RO scenario (right). Breakdowns of the stock of the materials into 6 product categories and the losses into 3 categories.

Fig. 3. Transitions dans la composition des stocks et des pertes d'acier, Ni et Cr au cours de la période de modélisation (50 ans). Les résultats du scénario BAU (à gauche) et du scénario $R O$ (à droite). Décompositions du stock de matériaux en 6 catégories de produits, ainsi que les pertes en 3 catégories.
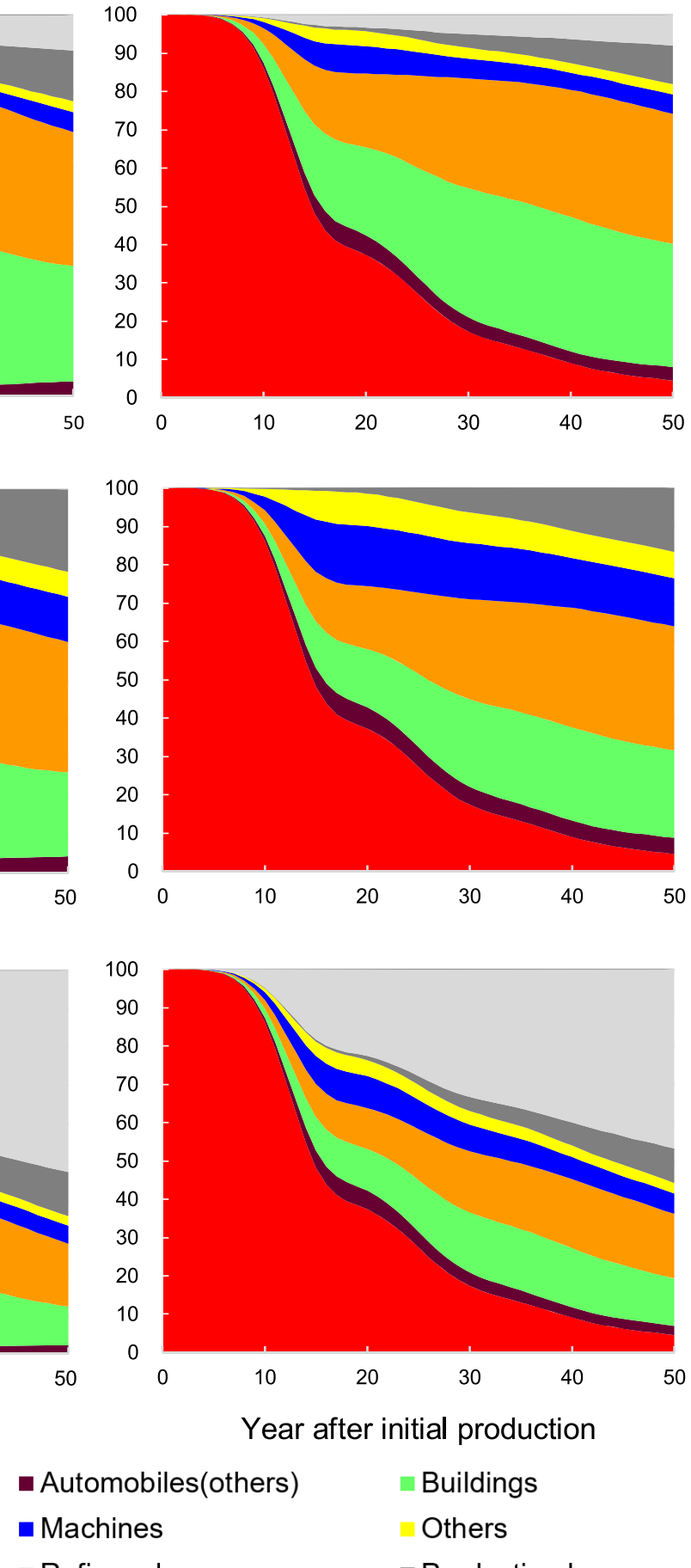

Buildings
Others

- Production loss 
and hardly any Ni to engines. Approximately $21 \%$ of the $\mathrm{Ni}$ was lost in the material recovery process. In comparison, the RO scenario shows that of the $99 \%$ of the stock of $\mathrm{Ni}$ in products, $38 \%$ appeared in engines, $46 \%$ in buildings, civil engineering structures, and machines, and the remainder in other products after 20 years. At the end of the period, $84 \%$ of $\mathrm{Ni}$ was accumulated in products, with buildings and civil engineering structures holding the largest stock segment of $55 \%$, while $16 \% \mathrm{Ni}$ out of the total had dissipated. It was found that the degree of reduction in material losses was almost the same in the two scenarios.

The bottom panel of Figure 3c illustrated less material stock and greater losses for Cr over time. In the BAU scenario, the portion of $\mathrm{Cr}$ retained in products after 20 years fell to $63 \%$, with nearly $0 \%$ used in engines, and $48 \%$ in buildings, civil engineering structures, and machines. The portion dropped continuously, reaching around $37 \%$ after 50 years, and the vast majority of this accumulated in buildings and civil engineering structures. Up to $63 \%$ of $\mathrm{Cr}$ was lost, and $52 \%$ of the losses occurred in the refining process. In the meantime, the percentage of recycled $\mathrm{Cr}$ under the $\mathrm{RO}$ scenario grew to $77 \%$ after 20 years, with engines sharing almost half of the total. After 50 years, as the percentage dipped to $45 \%$, Cr was found to be mainly stocked in buildings and civil engineering structures. The remaining 55\% was mostly lost during melting. The proportions of materials lost declined with the RO scenario, but the results showed little difference in between by the end of the modeling period.

Another important trend shows that the total loss was more than thrice as high for $\mathrm{Cr}$ as it was for Ni. Cr mostly oxidizes during remelting unlike $\mathrm{Ni}$, whereas $\mathrm{Ni}$ is primarily lost during the recovery process. The reason for this is that Cr-containing stainless steel is normally recovered as carbon steel, and thus, the $\mathrm{Cr}$ contained therein is apt to dissipate to slag in the refinery process. In contrast, $\mathrm{Ni}$ is very stable in molten iron and is quite difficult to remove from molten iron due to its thermodynamic properties. Hence, the majority of $\mathrm{Ni}$ is recycled within the $\mathrm{Ni}$ and stainless industries while a small portion becomes a minor constituent in carbon steel and copper alloys. The remaining non-recovered $\mathrm{Ni}$ ends up in a landfill, mainly in metal goods and waste household appliances and electronics. This outcome has also been noted in previous studies $[17,20,21,23,24]$.

Further, Ni was used more in machines and "others" than $\mathrm{Cr}$, which was more abundant in buildings and civil engineering structures, as shown in Figure 3. This is due largely to the WIO-MFA data on which the calculation is based. Moreover, Ni-containing stainless steel is usually utilized in machines requiring high temperature resistance and strong corrosion resistance. However, Cr-containing stainless steel, which is relatively inexpensive, is usually utilized in buildings and civil engineering structures. This point was carefully considered in this study.

In summary, although steel, $\mathrm{Ni}$, and $\mathrm{Cr}$ had different material dissipation pathways, the overall results indicated that the RO scenario had more or less the same effect as the BAU scenario on the reduction in dissipated material during the 50 years.

\subsection{Impacts on product service life extension potential}

As mentioned in Section 2.3, the ratio of the material recovered in engines to the total amount was used as a criterion for evaluating the life extension effects of products. In Figure 3, the share of material in engines over a 50-year period is highlighted in red (hereinafter referred to as the "engine area"). The total amount of material in products and losses over time corresponds to the whole area between the vertical and horizontal axes, which is emphasized with a range of colors (hereinafter referred to as "whole area"). In other words, the criterion can also be expressed as the ratio of the engine area to the whole area. More specifically, the engine area has been assigned to $\sum_{\tau=1}^{t} \iota_{i j \tau}$ while the whole area has been assigned to $\sum_{\tau=0}^{t} \sum_{i=1}^{n} \bar{x}_{i}(\tau)+\bar{l}(\tau)$, based on equation (4).

Figure 3a shows that in the BAU scenario, the volume of steel recovered in engines after 50 years was estimated at 1251, and the total amount was at 5000. Thus, the engine area accounted for $0.25(=1251 / 5000)$ of the total. This numerical value is low due to the fact that the share of steel in engines declined dramatically (close to 0) in 20 years. Compared to this result, a remarkable increase in the share of steel in engines was found the RO scenario. The share still comprised $38 \%$ after 20 years and $5 \%$ after 50 years. The calculated value of the engine area through the period increased to 2033 and that of the whole area to 5000. Thus, the ratio of the two areas was $0.41(=2033 / 5000)$, which was 1.6 times higher than the value in the BAU scenario.

The observations for $\mathrm{Ni}$ and $\mathrm{Cr}$ were essentially similar to those of steel with respect to their transitions in material stock in engines throughout the modeling period. As shown in Figures $3 \mathrm{~b}$ and $3 \mathrm{c}$, in the first 20 years, the fraction of both $\mathrm{Ni}$ and $\mathrm{Cr}$ retained in engines dropped to a mere $0.2 \%$ of the total under the BAU scenario, but showed an impressive $39 \%$ of the total under the RO scenario. Correspondingly, the engine areas for $\mathrm{Ni}$ and $\mathrm{Cr}$ in the figures were roughly equal, with a predicted value of 1251 under the BAU scenario and 2033 under the RO scenario after 50 years. Since the whole areas in Figures $3 \mathrm{~b}$ and $3 \mathrm{c}$ were equal (with a predicted value of 5000), the proportion of $\mathrm{Ni}$ in engines accounted for $0.25(=1251 / 5000)$ of the whole area in the BAU scenario but $0.41(=2033 / 5000)$ in the RO scenario. The same result was obtained for Cr. In brief, it was found that the RO scenario contributed 1.6 times the potential of the BAU scenario with regard to service life extension of products.

\section{Discussion}

This study demonstrated that when comparing the two different approaches of materials recovery, the results of material losses beyond 50 years are more or less equal. However, if we replace $40 \%$ out of $100 \%$ material recycling to parts reuse, greater possibilities would be achieved with respect to the service life extension of products when 
compared with $100 \%$ recycling. In fact, remanufacturing, refurbishment, repair, and direct reuse (RRRDR) practices to expand the product's service life would play key roles in the transition towards a circular economy [25]. The global remanufacturing industry has generated substantial economic value, amounting to a production value of 43 billion USD in the United States [26] and a European market value of 34 billion USD [27]. While the precise scale of the Japanese remanufacturing market is still unknown, sales of remanufactured automotive parts were estimated at approximately 1 billion USD [28], which is still well below from the global level.

To further promote the reuse of end-of-life products, designing for prolonged product lifetimes has become an increasingly important aspect of overall product development $[29,30]$. If product designs could be refined on a modular basis, a product could be divided into several modules, which would work independently from one another. Thus, they could be repaired, upgraded, and rebuilt separately into new designs and technologies without limiting each other's lifespans. Products should be designed with longer operational lifespans and durability to allow for multiple cycles of repurposing and even personalization. Thus, when these products reach the end of their service lives, their components would be disassembled and processed for remanufacturing. In this way, these remanufactured components would find a second life in a new product. The flexibility of these components would help extend the average lifetime of the products.

Design for recyclability is another important aspect for increasing the re-use of recovered materials. The vast majority of products eventually enter the recycling loop, and their component materials are extracted after a certain degree of reuse. Notably, recycling is a complex process, materials are lost at every step in this process, and the overall recycling efficiency also depends on the product design [15]. Thus, the properties of materials they are made of and the extent to which the materials are sorted and recovered are also vital considerations. Reducing quantities of complex materials, choosing materials with low environmental impacts during the usage phase, optimizing designs for easy disassembly, and indicating constituent materials within components to allow for easier material separation $[31,32]$ must be taken into account during the material selection stage of designing for recycling. Furthermore, the design should be based on an in-depth knowledge of metallurgy; the technical and economic feasibilities of recycling may considerably affect the extraction of recoverable materials from an alloy or at an elemental level. Thus, the higher the extent of recycling of high-quality materials in discarded products, the larger the quantities of secondary raw materials available for reuse as new resources for product manufacturing.

We end this paper by highlighting the methodological limitations and future tasks. There are two limitations. The first concerns the overestimation of used engines' lifetimes and used engines' current production yield ratios. The second limitation concerns the extension of average product lifetimes of automobiles, buildings, and civil engineering structures. The changes in their lifetimes and production yields would have considerable effects on the distribution of materials to final products and the final demand. Thus, a future task in our ongoing studies involves analyzing secondary production parameters for used products according to the MaTrace model, and improving the average lifetimes of several final products, including setting multiple lifetimes for directly reused parts and remanufactured parts. We also plan to use data from other countries in the MaTrace model to show the differences among various regions.

Acknowledgments. This research was supported by Japan Science and Technology Agency (JST-Mirai Program, Grant Number JPMJMI17C3) and the Japan Society for the Promotion of Science (KAKENHI 18H04147).

\section{References}

1. Ellen MacArthur Foundation, Towards the circular economy 1: Economic and business rationale for an accelerated transition, Ellen MacArthur Foundation, Cowes, Isle of Wight, UK, 2012

2. H. Schandl, et al., Decoupling global environmental pressure and economic growth: Scenarios for energy use, materials use and carbon emissions, J. Clean. Prod. 132, 45 (2015)

3. International Monetary Fund (IMF), Index charts, 20002017, Available from https://www.imf.org/external/np/res/ commod/Charts.pdf [accessed September 2018]

4. British Geological Survey, Risk list 2015 [online], 2015, Available from https://www.bgs.ac.uk/mineralsuk/statis tics/risklist.html [accessed September 2018]

5. Ellen MacArthur Foundation, Towards the circular economy 2: Accelerating the scale-up across global supply chains, Ellen MacArthur Foundation, Cowes, Isle of Wight, UK, 2014

6. W.R. Stahel, Circular economy, Nature 531, 436 (2016)

7. K. Nakajima, etal., Thermodynamic analysis for the controllability of elements in the recycling process of metals, Environ. Sci. Technol. 45, 4929 (2011)

8. H. Ohno, et al., Unintentional flow of alloying elements in steel during recycling of end-of-life vehicles, J. Ind. Ecol. 18 (2), $242(2014)$

9. S. Nakamura, et al., MaTrace: Tracing the fate of materials over time and across products in open-loop recycling, Environ. Sci. Technol. 48, 7207 (2014)

10. K. Takeyama, et al., Dynamic material flow analysis of nickel and chromium associated with steel materials by using Matrace, Materiaux \& Techniques 104, 610 (2017)

11. European Aluminium Association (EAA), Aluminium recycling, in: LCA, Version: September 2013, European Aluminium Association (EAA), Brussels, 2013

12. C. Gaudreault, Methods for open-loop recycling allocation in life cycle assessment and carbon footprint studies of paper products, Technical Bulletin No. 1003, National Council for Air and Stream Improvement, Inc (NCASI), Research Triangle Park, N.C., 2012

13. R. Geyer, et al., Common misconceptions about recycling, J. Ind. Ecol. 20(5), 1010 (2015)

14. C. Koffler, et al., Tackling the downcycling issue-A revised approach to value-corrected substitution in life cycle assessment of aluminum (VCS 2.0), Sustainability 2013 (5), 4546 (2013)

15. M.A. Reuter, et al., Limits of the circular economy: Fairphone modular design pushing the limits, MetallurgyERZMETALL 71, 2 (2018) 
16. M. Andersson, et al., Are scarce metals in cars functionally recycled?, Waste Manag. 60, 407 (2017)

17. S. Nakamura, et al., Quantifying recycling and losses of $\mathrm{Cr}$ and $\mathrm{Ni}$ in steel throughout multiple life cycles using MaTraceAlloy, Environ. Sci Technol. 51, 9469 (2017)

18. Ministry of the Environment (MOE) Government of Japan, The advanced utilization of the end-of-life vehicle originated scraps: as the technical report of MOE funded project "Advanced metal recycling technology development", Tohoku University, Sendai, Japan, 2012

19. Ministry of Internal Affairs and Communications Government of Japan, 2005 Input-Output Tables for Japan (in Japanese). Research Institute of Economy, Trade and Industry, Available from http://www.soumu.go.jp/toukei_toukatsu/data/io/ 005index.htm [accessed September 2018], 2009

20. T. Oda, etal., Substance flow and stock of chromium associated with cyclic use of steel in Japan, ISIJ Int. 50(2), $314(2010)$

21. I. Daigo, et al., Substance flow analysis of chromium and nickel in material flow of stainless steel in Japan, Resour. Conserv Recycl. 54, 851 (2010)

22. Ministry of Economy, Trade and Industry (METI) Government of Japan, Survey of the circulation of metal resources from end-of-life vehicles in Japan FY2014 (in Japanese), 2015, pp. 41-52

23. B.K. Reck, et al., Anthropogenic nickel cycle: Insights into use, trade, and recycling, Environ. Sci. Technol. 42, 3394 (2008)
24. K. Nakajima, et al., Simultaneous material flow analysis of nickel, chromium, and molybdenum used in alloy steel by means of input-output analysis, Environ. Sci Technol 47, 4653 (2013)

25. K. Nakajima, et al., Development of multi-value circulation based on remanufacturing, 12th International Conference on Society \& Materials, SAM12, 2018

26. United States International Trade Commission (USITC), Overview of U.S. Remanufacturing Activities, in: Remanufactured goods: An overview of the U.S. and global industries, markets, and trade, investigation No.332-525, USITC Publication 4356, 2012, pp. 2-3

27. European Remanufacturing Network (ERN), Remanufacturing market study, Oakdene Hollins Ltd., Aylesbury, UK, 2015

28. Yano Research Institute Ltd., Automotive Aftermarket 2017, 2017

29. European Union, Directive 2009/125/EC of the European Parliament and of the Council of 21 October 2009, 2009

30. P. Lacy, et al., Waste to wealth: The circular economy advantage, Palgrave Macmillan, London, UK, 2015

31. U. Tischner, et al., Sustainable electronic product design, in: V. Goodship, A. Stevels (Eds.), Waste electrical and electronic equipment (WEEE) handbook, Woodhead Publishing, Cambridge, UK, 2012, pp. 405-441

32. E. Maris, et al., From recycling to eco-design, in: E. Worrell, M.A. Reuter (Eds.), Handbook of recycling, Elsevier, Waltham, USA, 2014, pp. 421-427

Cite this article as: Zhengyang Zhang, Kentaro Takeyama, Hajime Ohno, Kazuyo Matsubae, Kenichi Nakajima, Tetsuya Nagasaka, An estimation of the amount of dissipated alloy elements in special steel from automobile recycling, Matériaux \& Techniques 107, $105(2019)$ 